\title{
Distribution and Antibiotic Susceptibility Profiles of Vibrio Species Isolated from Selected Abattoirs in Akoko South-West, Ondo State, Nigeria
}

\section{Osunla Charles Ayodeji*}

Department of Microbiology, Adekunle Ajasin University, Ondo State, Nigeria

*Corresponding Author: Osunla Charles Ayodeji, Department of Microbiology,

Adekunle Ajasin University, Ondo State, Nigeria.
Received: September 22, 2021

Published: October 14, 2021

(C) All rights are reserved by Osunla Charles Ayodeji.

\begin{abstract}
Many Vibrio species are pathogenic to humans and have been implicated in food-borne disease. They are naturally found in the estuarine and marine environment. The aim of this study is to study the distribution and antibiotics susceptibility profiles of Vibrio species recovered from two selected abattoirs in Akoko Southwest. A total of fifteen (15) samples consisting of Slab swabs $(\mathrm{n}=4)$, Meat $(\mathrm{n}=$ 4), Effluent ( $n=4)$, and Knife ( $n=3)$ were collected from Abattoirs in Akungba and Iwaro-Oka Akoko. Bacteriological investigation was carried out in accordance with the microbiological standard method by serially diluted each sample in test tubes filled with $9 \mathrm{ml}$ of enrichment medium (Alkaline Peptone Water) and were isolated through the use of TCBS agar which is one of the recommended media for the selective isolation of Vibrio species. The overall proportion of Vibrio positive isolates was $86.67 \%$ in all samples, of which $100 \%$ were from effluent and meat, $75 \%$ slab and $66.67 \%$ knife. It was observed that more Vibrio spp. were isolated from the meat and effluent discharged than from other sources. The bacteria (Vibrio species) isolated were subjected to various biochemical tests and were also subjected to antimicrobial susceptibility tests. The isolates showed resistance to multiple antibiotics, and the susceptibility pattern of the isolates to different antibiotics was tested and interpreted using the disk diffusion method (Kirby-Bauer) described by the Clinical and Laboratory Standards Institute. It was observed that the organisms were susceptible to Imipenem, Nitrofurantoin, Ciprofloxacin, Azithromycin and Augumentin. Moreso, of the identified Vibrio species large percentage showed resistance to Tetracycline and Ampicillin. This study clearly indicated and concluded that the meat and the effluents discharged from these abattoirs to the environment are reservoir for Vibrio species as well as antibiotics resistance genes. The high distribution of resistant vibrios in these abattoirs shows potential public health hazards. Therefore, there is an urgent need to establish a sanitation and hygienic intervention majorly focused on limiting the rate of contamination of the slaughtered animal in causing human illness when in contact with, and also to adopt a strategies that are effective in eliminating antibiotics resistant Vibrios species.
\end{abstract}

Keywords: Abattoir; Vibrio Species; Antibiotics Resistance; Effluent; Meat

\section{Introduction}

The genus Vibrio are gram-negative, facultative anaerobic, nonspore-forming bacilli that are oxidase positive and halophilic. Vibrios are generally salt-tolerant organisms occurring naturally in marine and brackish water environments in both tropical and tem- perate regions, although Vibrio cholerae and Vibrio mimicus also occur in freshwater. Vibrios have also been isolated from sediments, plankton, molluscs, finfish and crustaceans [1,2]. Many of the Vibrio species are pathogenic for mankind and are usually responsible for causing alimentary infections in countries with warm coastal wa- 
ters, where fish and shellfish are consumed raw or lightly cooked [3]. Currently, 12 species of Vibrio are known to be associated with human infections acquired by consumption of contaminated foods and water. Vibrio species were reported for the first time in Japan as the cause of gastroenteritis, where Vibrio parahaemolyticus was implicated as the cause of at least one-quarter of total foodborne diseases, mostly after the consumption of raw or undercooked seafood [1]. An abattoir is a special facility designed and licensed for receiving, holding, slaughtering and inspecting meat animals and meat products before release to the public. Abattoir inspection of live animals (ante-mortem) and carcass (post-mortem) are critical to surveillance for animal diseases and zoonoses [4]. [5] reported that pathogens of zoonotic importance are associated with more than $80 \%$ of public abattoirs in Nigeria. This observation has serious public health implication as many Nigerian abattoirs dispose their effluents directly into streams and rivers without any form of treatment. Incidentally, these streams and rivers also serve as water resource for domestic, agricultural, recreational as well as drinking purposes for communities and settlements downstream. Meat is a nutritious, protein-rich food which provides the nutrients needed to support the growth of many types of microorganisms. This attribute makes meat highly perishable, having a short shelf life unless preservation methods are used [6]. The microbiological quality of meat depends on the physiological status of the animal at slaughter, the spread of contamination during slaughter and processing, the temperature and other conditions of storage and distribution [7]. Contaminated raw meat is one of the main sources of zoonotic food borne illness [8] and food borne pathogens are the leading cause of illness and death in developed and developing countries with attending high cost medically and socially [9].

Antibiotic resistance levels are also elevated among food-borne pathogen. Though the link between drug resistance in bacteria contaminating food items and increased clinical cases of resistant infections not fully defined; so the presence of bacteria in food items and their environment might play a role in the spread of antimicrobial resistance amongst food-borne pathogens and other microorganisms $[9,10]$. [11,12] in a literature report suggested that abattoir were important environmental reservoirs for Vibrio species. And given the proposition that environmental reservoir of toxigenic Vibrio species and/or non-enterotoxigenic environmental Vibrio strains may serve as progenitors for future enterotoxin producing epidemic strains, it becomes imperative to monitor abattoir for potential Vibrio pathogens. This study was designed to know the distribution and antibiotics susceptibility profile of Vibrio species isolated from abattoirs in Akoko South-West, Ondo State, Nigeria.

\section{Materials and Methods}

Study area

This research covered two selected abattoirs in Akoko Southwest, Ondo State. These include Akungba Akoko and Iwaro-Oka Akoko abattoir.

\section{Sample collection}

After due permission and approval from the abattoir personnel, samples were collected between April to July, 2021 using sterile universal sample bottles, swab sticks, ziplock bag. The samples were immediately transported for further testing in the laboratory. The effluent collected was serially diluted adopting the ten-fold serial dilution method with sterile diluted water, and the diluents are sequentially homogenized at maximum speed for two minutes.

\section{Isolation of Vibrio species}

$1 \mathrm{ml}$ of the stock sample was introduced into $9 \mathrm{ml}$ of water in test tubes, and was serially diluted. One hundred microlitre of each dilution factors was dispensed into sterilized $9 \mathrm{ml}$ of alkaline peptone and incubated overnight at $37^{\circ} \mathrm{C}$ for 24 hours and later streaked out on prepared TCBS agar plates. This medium was allowed to gelled and later incubated at $37^{\circ} \mathrm{C}$ for 24 hours. A maximum of two Vibrio colonies were distinctly selected and subcultured on a fresh TCBS agar and, purified repeatedly on Nutrient Agar.

\section{Presumptive identification of Vibrio species}

All recovered Vibrio isolates were subjected to biochemical (catalase, oxidase, indole, citrate and sugar fermentation test) and morphological and cultural (colony) characterization [13].

\section{Antimicrobial susceptibility profile of the Vibrio isolates}

Antimicrobial susceptibility profile of the Vibrio species was carried out using Kirby-Bauer disc diffusion method. Briefly, the purified isolates were inoculated on $5.0 \mathrm{ml}$ Mueller-Hinton Broth (Oxoid, UK) and incubated overnight. The optical density (OD) of the turbidity of the broth was determined to conform with the OD $0 \cdot 5$ of the McFarland standard where the cells were equivalent to $106 \mathrm{cfu}$ per ml. Using a sterile swab sticks, respective broth cultures were aseptically swabbed on Mueller-Hinton Agar (Oxoid). A total of 24 antibiotic discs (Davies Diagnostics, Randburg, SA) which includes Ampicillin $(25 \mu \mathrm{g})$, Tetracycline $(30 \mu \mathrm{g})$, Ciprofloxa-

Citation: Osunla Charles Ayodeji. "Distribution and Antibiotic Susceptibility Profiles of Vibrio Species Isolated from Selected Abattoirs in Akoko South-West, Ondo State, Nigeria". Acta Scientific Microbiology 4.11 (2021): 25-29. 
cin $(5 \mu \mathrm{g})$, Augumentin $(30 \mu \mathrm{g})$, Azithromycin $(15 \mu \mathrm{g})$, Nitrofurantoin $(100 \mathrm{I} \mu)$ and Imipenem $(10 \mu \mathrm{g})$ were used for the susceptibility testing. The respective discs were also aseptically seeded on the agar plates using a sterile antibiotics dispenser (Davies Diagnostics, Randburg, SA).

\section{Results}

Table 1 shows the distribution pattern of Vibrio species on abattoir samples collected from Akungba and Iwaro-Oka Akoko. Thirty (30) isolates were recovered from the twelve abattoir samples of knife, meat, slab and effluent. The meat and effluent samples were all (100\%) contaminated by Vibrio species, while two-third of the knife and the slab samples were contaminated by Vibrio.

\begin{tabular}{|l|c|c|c|}
\hline Sample & No examined & No positive & \% contamination \\
\hline Knife & 3 & 2 & 66.67 \\
\hline Meat & 4 & 4 & 100 \\
\hline Slab & 4 & 3 & 75 \\
\hline Effluent & 4 & 4 & 100 \\
\hline Total & 15 & 13 & 86.67 \\
\hline
\end{tabular}

Table 1: Distribution of Vibrio species in Abattoir Samples

Table 2 show the interpretation of the zones of inhibition diameter using the Clinical Laboratory Standard Institute CLSI. (2015) guidelines and percentage resistance of the isolates against the antibiotics used respectively. The zones of inhibition diameter were interpreted as susceptible, intermediate or resistant. While all the isolates used for Antibiotic susceptibility test were susceptible to Imipenem and also resistant to Tetracycline.

\begin{tabular}{|c|c|c|c|}
\hline \multicolumn{4}{|c|}{ Zone of inhibition diameter (mm) } \\
\hline Antibiotic & Susceptible & Intermediate & Resistance \\
\hline Augmentin $30 \mu \mathrm{g}$ & $\geq 18$ & $14-17$ & $\leq 13$ \\
\hline Azithromycin $15 \mu \mathrm{g}$ & $\geq 16$ & $13-15$ & $\leq 12$ \\
\hline Nitrofurantoin 100 & $\geq 18$ & $15-17$ & $\leq 14$ \\
$\mathrm{I} \mu$ & & \\
\hline Tetracycline $30 \mu \mathrm{g}$ & $\geq 15$ & $12-14$ & $\leq 11$ \\
\hline Imipenem $10 \mu \mathrm{g}$ & $\geq 18$ & $13-17$ & $\leq 12$ \\
\hline Ampicillin $10 \mu \mathrm{g}$ & $\geq 17$ & $14-16$ & $\leq 13$ \\
\hline Ciprofloxacin $5 \mu \mathrm{g}$ & $\geq 21$ & $16-20$ & $\leq 15$ \\
\hline
\end{tabular}

Table 2: Interpretation of zones of inhibition diameter according to CLSI guidelines (2015).

(Source: Clinical Laboratory Standard Institute (CLSI, 2015).

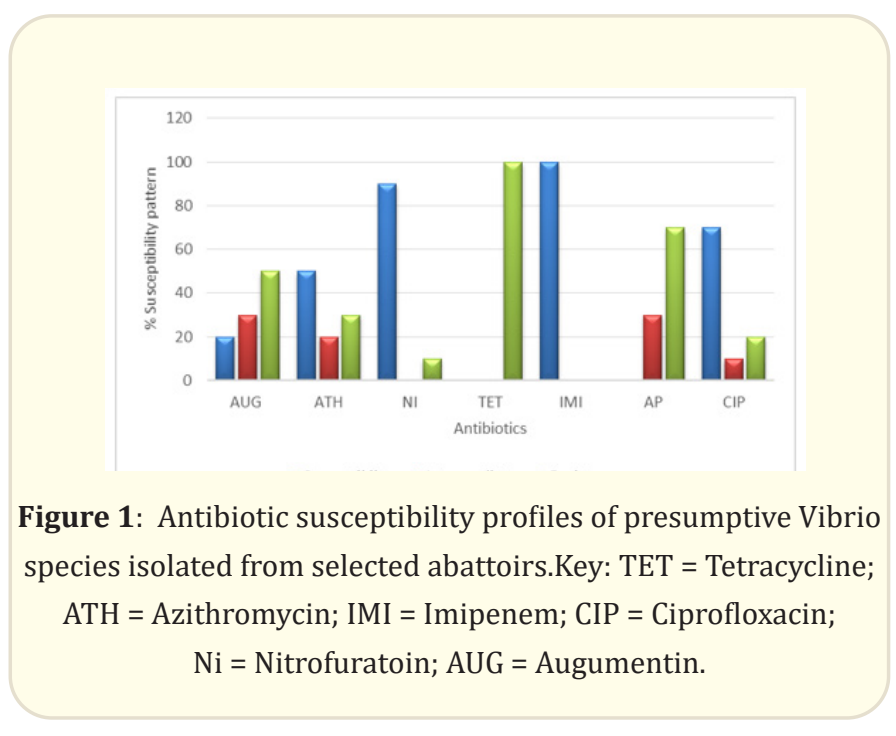

\section{Discussion}

The members of the genus Vibrio have been frequently defined as opportunistic and potential pathogenic bacteria. Therefore, from the public health perspective, the occurrences of these bacteria have caused concerns for authorities. The increase of Vibrio infections due to the consumption and the manipulation of contaminated meat and water have made necessary the precise identification of Vibrio species. A correct monitoring of Vibrio species in abattoir products could open new interesting perspectives for epidemiological studies on the principal risk factors associated with these microorganisms [1]. The isolation and identification of the isolates followed microbiological standards; Vibrio species were isolated through the use of TCBS agar which is one of the recommended media for the selective isolation of Vibrio species [14]. The findings in this study confirmed the presence of Vibrio species in all the abattoir samples. The danger that comes with the abundance of Vibrio species in abattoir effluents in the release of enterotoxins known to cause serious illness of three major clinical syndromes i.e. gastroenteritis, wound infection and septicaemia [15]. According to [16], Vibrios is has been considered to be an emerging foodborne infection and has become a high public hazard all over the world, especially in coastal areas of developing countries and region with poor sanitation. Therefore, the high level occurrence of Vibrio species in abattoir effluents can pose a significant economic threat. The presences of Vibrio species are mixed in abattoir indicate that the mode of transmission in the food chain is via contaminated water and food [17]. 
The susceptibility pattern of the Vibrio species against antibiotics revealed that the organisms were $100 \%$ susceptible to Imipenem, $90 \%$ susceptible to Nitrofurantoin, $70 \%$ susceptible to Ciprofloxacin, 50\% to susceptible Azithromycin, 20\% susceptible to Augumentin and not susceptible to Tetracycline and Ampicillin. This result is closely related to findings of [18] on the intensive use to antibiotics in general environmental samples. The result also showed that all Vibrio isolates exhibited resistance to more than three antibiotics; this includes $100 \%$ resistance to Tetracycline, 70\% resistance to Ampicillin, 50\% resistance to Augumentin, 30\% resistance to Azithromycin, 20\% resistance to ciprofloxacin, 10\% resistance to Nitrofurantoin and $0 \%$ resistance to Imipenem.

Tetracycline is one of the most popular antibiotics used in hospital (as a drug of choice in treating cholera), home and aquaculture for its effectiveness over a broad spectrum of pathogen at low cost [19]. However, in this study it was not effective against any of the test organisms as there is an increased in resistance among pathogens, with similar report by [20]. Our findings showed that Vibrio species have varied resistance against tetracycline and ampicillin.

From the public health view, Vibrio infection have been a common problem because its mostly isolated from various environmental sources such as foods, human mucosa, farm animal, aquaculture environment and wastes, which is of significant health concern as these emerging strains have developed resistance to various antibiotics that may help in human medicine. Therefore, antibiotics such as Imipenem is considered to be the best medicine in the case of gram negative bacterial infections because of its broad spectrum effects and mechanism of action, and the less probability to develop resistance by bacteria unless an efflux is developed.

According to [5], abattoir effluents are important reservoirs of multidrug resistant Vibrio pathogens. This implies that abattoir effluents could be important contributors to the recurrent episodes of epidemic cholera and non-Vibrio cholerae outbreaks in Nigeria. Therefore, thorough surveillance initiative by relevant stakeholders to elucidate the extent to which abattoir effluents contribute to the spread and recurrence of epidemic vibriosis in Nigeria (and possibly elsewhere) with a view to arresting the scourge of vibriosis (including cholera) in our society.

\section{Conclusion}

The results indicate that potentially pathogenic Vibrios found in the meat and effluents from these abattoirs. The consumption of the meats contaminated and the release of the effluents to the environment pose a great risk for public health. Abattoir remains the means of transmission of Vibrio species infection and is a potential source and reservoir of antibiotics resistant bacteria which pose a threat to public health. The development and transfer of resistant gene in Vibrio species occur as a result of indiscriminate use of chemotherapeutic agent in homes, hospitals, aquaculture and agriculture. Therefore, abattoir wastes should be properly treated before it is released into the environment and efficient waste management techniques should be adopted in the Abattoirs in Nigeria.

\section{Bibliography}

1. Mehdi R., et al. "Occurrence of Vibrio spp. in lobster and crab from the Persian Gulf". Journal of Food Safety 32 (2012): 198203.

2. Maiti B., et al. "Evaluation Of Rapd-Pcr And Protein Profile Analysis To Differentiate Vibrio Harveyi Strains Prevalent Along The Southwest Coast Of India". Journal of Genetics 88 (2009): 273-279.

3. Passalacqua P L., et al. "Occurrence of Vibrio parahaemolyticus, Vibrio cholerae and Vibrio vulnificus in the Clam Ruditapes Philippinarum (Adams \& Reeve, 1850) from Emilia Romagna and Sardinia, Italy". Italian Journal of Food Safety 5 (2016): 5709.

4. Iroha IR., et al. "Bacterial contamination of raw meat sold in Abakaliki, Ebonyi State Nigeria”. Journal of Public Health and Epidemiology 3 (2011): 49-53.

5. Odjadjare EE., et al. "Multidrug-resistant Vibrio species isolated from abattoir effluents in Nigeria". Journal of Infection in Developing Countries 11.5 (2017): 373-378.

6. Olaoye $\mathrm{OA}$ and Onilude AA. "Investigation on the potential application of biological agents in the extension of shelf life of fresh beef in Nigeria". World Journal of Microbiology and Biotechnology 26 (2010): 1445-1454.

7. Koutsoumanis KP and Sofos JN. "Comparative acid stress response of Listeria monocytogenes, Escherichia coli 0157: H7 and Salmonella Typhimurium after habituation at different $\mathrm{pH}$ conditions". Letters in Applied Microbiology 38.4 (2004): 321326. 
8. Hassan AN., et al. "Microbial contamination of raw meat and its environment in retail shops in Karachi, Pakistan". Journal of Infection in Developing Countries 4 (2010): 382-388.

9. Fratamico PM., et al. "Foodborne pathogens in microbiology and molecular biology". Caister Academic Press, Wymondham, Norfolk, UK (2015): 273.

10. Farzana K., et al. "Prevalence and antibiotic resistance of bacteria in two ethnic milk based products". Pakistan Journal of Botany 41 (2009): 935-943.

11. Atieno NR., et al. "Isolation of high antibiotic resistant faecal bacteria indicators, Salmonella and Vibrio species from raw abattoirs sewage in peri-urban locations of Nairobi, Kenya, Greener". Journal of Biological Sciences 3.5 (2013): 172-178.

12. Ogbonna DN. "Distribution of microorganisms in water, soils and sediment from abattoir wastes in southern Nigeria". International Journal of Current Microbiology and Applied Sciences 3.9 (2014): 1183-1200.

13. Cheesbrough M. Microbiological test. In District Laboratory Practice in Tropical Countries; Part II. New York, NY, USA: Cambridge University Press (2000).

14. Ottaviani D., et al. "A biochemical protocol for the isolation and identification of current species of Vibrio in seafood". Journal of Applied Microbiology 95.6 (2003): 1277-1284.

15. Daniels NA and Shafaie A. "A review of pathogenic Vibrio infections for clinicians". Infections in Medicine 17.10 (2000): 665685.

16. Osunla CA and Okoh AI. "Vibrio pathogens: A public health concern in rural water resources in sub-Saharan Africa". International Journal of Environmental Research and Public Health 14.10 (2017): 1188.

17. Chowdhury G., et al. "Vibrio fluvialis in patients with diarrhea, Kolkata, India”. Emerging Infectious Diseases 18.11 (2012): 1868.

18. Kraemer SA., et al. "Antibiotic pollution in the environment: from microbial ecology to public policy". Microorganisms 7.6 (2019): 180.
19. Neela FA., et al. "The diversity of multi-drug resistance profiles in tetracycline-resistant Vibrio species isolated from coastal sediments and seawater". Journal of Microbiology-Seoul 45.1 (2007): 64.

20. Bhattacharya SK. "An evaluation of current cholera treatment". Expert Opinion on Pharmacotherapy 4.2 (2003): 141-146.

\section{Volume 4 Issue 11 November 2021 (CAll rights are reserved by Osunla Charles Ayodeji.}

